\title{
Establishment of the forensic odontology department: A proposed model for the basic infrastructure and forensic odontology kit
}

\author{
Jayasankar \\ Purushothaman Pillai, \\ Thamarai Selvan \\ Chokkalingam ${ }^{1}$, \\ Balamurugan Aasaithambi², \\ Emilio Nuzzolese ${ }^{3}$ \\ Department of Oral Pathology, \\ Government Dental College \\ and Hospital, Ahmedabad, \\ Gujarat, 'Department of \\ Forensic Odontology, Maulana \\ Azad Institute of Dental \\ Sciences, New Delhi, ${ }^{2}$ Forensic \\ Odontologist and Dental \\ Practitioner, Thanjavur, \\ Tamil Nadu, India, ${ }^{3}$ Department \\ of Public Health Sciences and \\ Pediatrics, University of Turin, \\ Turin, Italy
}

\section{Address for correspondence: Dr. Jayasankar Purushothaman Pillai, \\ Department of Oral Pathology, Government Dental College and Hospital, Ahmedabad - 380 016, Gujarat, India. \\ E-mail: jppillaigdch@gmail.com}

\begin{abstract}
The importance and the application of dental science and forensic odontology in the legal system are gradually increasing in India. In a long-term vision, there is a need for a specialized forensic training curriculum not only for the undergraduate and postgraduate dental students but also for the experienced dental surgeons. Dental experts opinion is sought most commonly in forensic casework of human identification, age estimation, and sexual assault cases with patterned injury, by the legal and forensic authorities. As a consequence, there is a demand for dentists trained in forensic and legal dentistry and experienced in forensic, capable of dealing and managing medicolegal cases in dental institutes or state hospitals. Several guidelines and protocols for forensic odontology procedures are drafted and proposed by forensic odontology organizations. However, there are no specific guidelines or recommendations for the establishment of a specialized forensic odontology department or unit in dental institutes. Hence, this article addresses the necessity and requirements for a forensic odontology unit, proposing a model to follow. A comprehensive list of forensic odontology armamentarium and case dependent forensic odontology kits is also highlighted here.
\end{abstract}

Key words: Dental anthropology, forensic odontology, odontology kit

\section{Introduction}

$\mathrm{T}$ he Federation Dentaire Internationale defines forensic odontology as that branch of dentistry which, in the interest of justice, deals with the proper handling and examination of dental evidence, and with the proper evaluation and presentation of dental findings. ${ }^{[1]}$ It is a subdiscipline of dental science which involves a multidisciplinary approach while handling forensic dental

\begin{tabular}{|l|c|}
\hline \multicolumn{3}{|c|}{ Access this article online } \\
\hline \multirow{2}{*}{$\begin{array}{l}\text { Website: } \\
\text { www.jfds.org }\end{array}$} & Quick Response Code \\
\hline \multirow{2}{*}{$\begin{array}{l}\text { DOI: } \\
\text { 10.4103/jfo.jfds_53_19 }\end{array}$} & \\
\hline
\end{tabular}

evidence and presenting the report to the court of law. In India, there are 313 dental institutes with nearly 1.3 lakhs dental students and more than 2.7 lakhs dentist workforce ${ }^{[2]}$ and no dental institute is yet offering a council-recognized master's program for forensic odontology. However, there
Submitted: 19-Jun-19
Accepted: 23-Oct-19
Revised: 02-Oct-19
Published: 24-Jan-20

This is an open access journal, and articles are distributed under the terms of the Creative Commons Attribution-NonCommercial-ShareAlike 4.0 License, which allows others to remix, tweak, and build upon the work non-commercially, as long as appropriate credit is given and the new creations are licensed under the identical terms.

\section{For reprints contact: reprints@ @medknow.com}

How to cite this article: Pillai JP, Chokkalingam TS, Aasaithambi B,
Nuzzolese E. Establishment of the forensic odontology department:
A proposed model for the basic infrastructure and forensic
odontology kit. J Forensic Dent Sci 2019:11:64-72. 
Pillai, et al.: Proposed plan for establishing forensic odontology department

are several certificates, diplomas and fellowship programs in forensic odontology, being offered by some organizations and associations regularly throughout the country. To address the dearth of qualified forensic odontologists in the country, some Indian universities are also offering postgraduate (MSc.) course ${ }^{[3,4]}$ and postdoctoral fellowship ${ }^{[5]}$ training in forensic odontology with curriculum covering the dental, forensic and legal disciplines. Besides, there are some foreign-trained forensic odontologists, mostly graduating from countries such as Australia, Belgium and UK, who are offering forensic services and giving new dimensions to the science of forensic odontology in India. Currently, forensic odontology has not been introduced as a separate subject in undergraduate curriculum. ${ }^{[6]}$ The revised bachelor of dental surgery (BDS) course regulation of 2007 included forensic odontology as a syllabus of study (No. 20) with 10-12 h of didactic sessions and 20-25 h of practical sessions. ${ }^{[7]}$ The syllabus is being covered in two separate streams with the first preclinical stream in the $1^{\text {st }}$ and/or $2^{\text {nd }}$ BDS years by the oral pathology department and the clinical stream in the final year by the oral medicine and radiology department. Qualifying is the key step in the development of professional expertise in any field of dentistry and the same may be applicable for forensic odontology, too. Unfortunately, the masters or diploma courses in forensic odontology currently offered in India and abroad are not recognized by the dental apex body of the country. It is because the duration of the course is not on par with the master's course (3 years) or diploma (2 years) offered in India. Due to rising demand for the forensic dental services in the present Indian social conditions, ${ }^{[6]}$ there is mushrooming of training and continuing dental education (CDE) programs in forensic odontology through dental institutes and associations. Even though this is the stand on one side, on the other hand, some of the dental institutes including the premier dental institutes of the country are establishing a separate forensic odontology unit or department under the aegis of oral pathology and oral medicine departments. The forensic odontologists trained in India and abroad are recruited as faculty in such departments. The first of its kind in India, an exclusive department of forensic odontology, was commenced in 2006 at SDM College of Dental Sciences, Dharwad, which is headed by an Australian-trained forensic odontologist. ${ }^{[8]}$ The first three authors of this article had an opportunity to visit the department and got trained under the same forensic odontologist. Such a department not only teaches the subject to the undergraduate and postgraduate students but also handles forensic cases referred from the home/legal department and the forensic medicine departments of medical colleges. Few forensic odontologists trained in India and abroad are also posted in the forensic medicine departments of the medical colleges and as a team perform the biological profiling of the deceased during postmortem examination and also render their expert service in other areas of forensic odontology. A multidisciplinary approach along with the forensic medicine department, forensic science laboratories (FSLs), forensic anthropology department and the legal department is mandatory for the successful evolution of forensic odontology in any country. Most dental institutes do not have the necessary proficiency to deal with forensic cases and their students are not practically exposed to the legal proceedings in the court of law, unlike the medical institutes. The qualified dental surgeons were also not practically trained to handle dental evidence in forensic cases during their dental curriculum. This gap needs to be addressed by establishing an exclusive forensic odontology department or unit in all the dental institutes and by recruiting qualified forensic odontologists that may impart forensic odontology knowledge to the dental students. The department can also provide training to the external candidates highlighting the forensic attributes of dental evidence. In a dental institute, the forensic odontology unit is recommended to function under the aegis of the oral pathology and oral medicine departments with forensic support from the medical institute [Figure 1]. However, the infrastructural facilities of almost all the clinical and nonclinical departments in a dental institute are recommended to be utilized for the proper functioning of the forensic odontology unit. Thus, the evolved forensic odontology units need to deliver core theoretical knowledge and intellectual skills to the dental students and the trainees to prepare them competent enough to handle forensic cases, whenever consulted by the forensic and legal authorities. The infrastructure facilities of the department need to be sufficient enough to impart the practical hands-on experience and also to handle real-life forensic case works and represent the same to the court of law. To this end, the facility must establish operative agreements on specific multidisciplinary medicolegal evaluations, among which human identification process of decomposed, carbonized and skeletonized human remains. The unit must be ready to collaborate with all or some of the following specialists, holding experience, education and training in the forensic process: medical examiner or forensic pathologist, forensic anthropologist, forensic photographer, police crime scene investigator, evidence technician/gatherer, fingerprint expert, DNA analyst, radiologist and radiographic technician, toxicologist and also dental hygienist/assistant. ${ }^{[9]}$

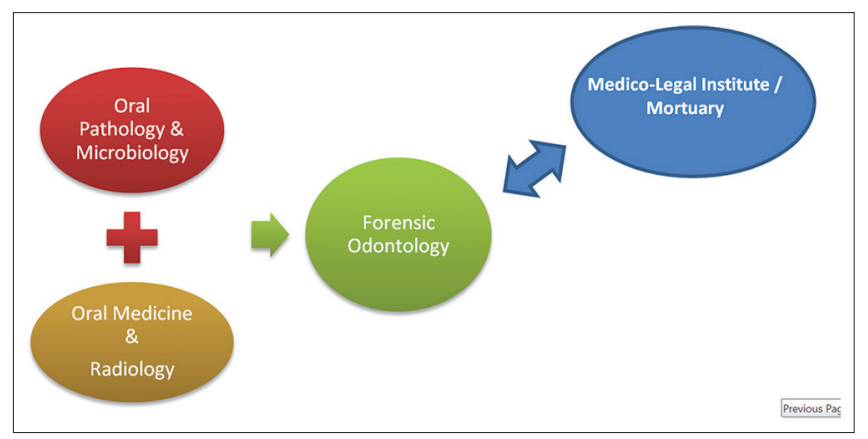

Figure 1: Linking of forensic odontology branch with other related branches 
Pillai, et al.: Proposed plan for establishing forensic odontology department

The following components are necessary for an ideal forensic odontology department:

1. Theoretical or academic component: to impart theoretical knowledge on various aspects of forensic medicine, odontology, disaster victim identification (DVI), and anthropology to the students and trainees in the form of lectures, seminars, and assignments as per the revised 2007 BDS course regulations. Some informative sessions on Civil and Penal Code and Judicial proceedings, specific to medical or dento-legal aspects may be highlighted.

2. Practical component: to impart practical skill and train the dental students and the trainees on the methodological approaches in age estimation, gender determination, bite mark analysis, dental identification, and report writings and also to handle the real-time forensic cases. The department may be associated with the medicolegal/forensic medicine department of the nearby medical college and the state forensic sciences laboratories (FSLs). A training in the dental autopsy, forensic radiology, and teamwork with law enforcement agencies and other forensic experts may also be included.

3. Research component: to assist the postgraduate students and independent researchers to take up research projects on the topics related to forensic odontology and forensic radiology.

\section{Infrastructure}

The basic design of the forensic odontology department and the forensic odontology kit was prepared bearing in mind the syllabus for the undergraduate and postgraduate students in dental colleges, conditions of the various forensic dental specimens (living and deceased) to evaluate and observe, and to have a clean and safe working environment [Figures 2 and 3].

The department may be located in the dental college or near the mortuary of the medical college or hospital within the campus. The primary circulation or the exit corridor leading to the department may be of $6 \mathrm{ft}$ wide, minimum and the

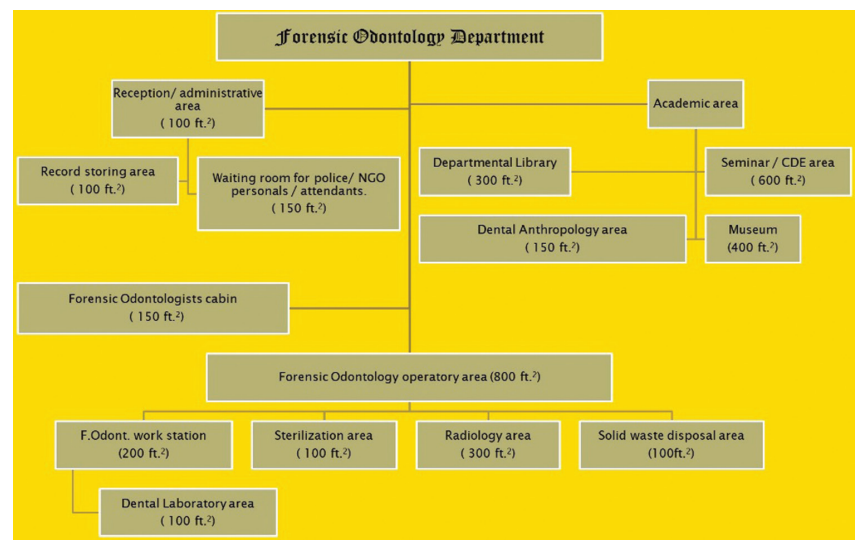

Figure 2: An example of a proposed plan for establishing the forensic odontology department in a dental/medical institute secondary circulation or non exit corridor may be of $4.5 \mathrm{ft}$ wide, minimum. Considering the evolving trends in the conventional methods used in forensic odontology, ${ }^{[10]}$ a basic infrastructure and armamentarium list for a forensic odontology unit is proposed here. It may include the following:

1. Administrative area
a. Reception $(12 \times 14 \mathrm{sq} . \mathrm{ft})$
b. Record room $(12 \times 10 \mathrm{sq} f \mathrm{ft})$
c. Waiting room for police, non-governmental organizations representatives, media personnel and families $(12 \times 12 \mathrm{sq}$. ft).

2. Dental operatory area

a. Odontologist's cabin $(12 \times 20$ sq. $\mathrm{ft})$

b. Odontologist's changing room having bath with shower and locker facility $(12 \times 10 \mathrm{sq} . \mathrm{ft})$

c. Operatory cubicle/workspace $(30 \times 30 \mathrm{sq} . \mathrm{ft})$

d. Evidence (specimen/victim/accused) examination room with dental chair (150 sq. $\mathrm{ft}$ )

e. Storeroom $(12 \times 10$ sq. $\mathrm{ft})$

f. Radiology area (300 sq. ft)

g. Sterilization area (250 sq. $\mathrm{ft})$

h. Solid disposal area (250 sq. ft)

i. Rest area (200 sq. ft).

3. Academic area
a. Seminar hall (600 sq. ft)
b. Departmental library (300 sq. ft)
c. Departmental museum/display area (600 sq. $\mathrm{ft}$ ).

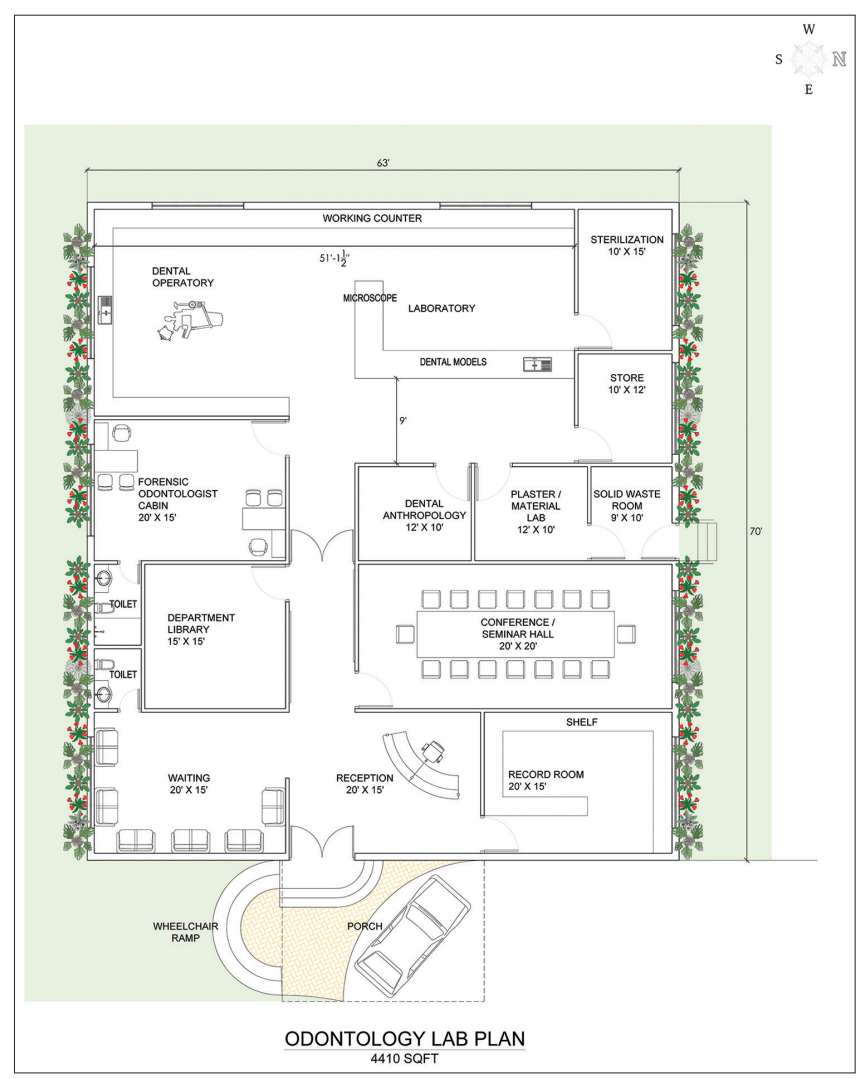

Figure 3: An architect's model plan of a forensic odontology department 
Pillai, et al.: Proposed plan for establishing forensic odontology department

4. Dental and anthropological laboratory area

a. Biotech laboratory with high-efficiency particulate air filter and laminar hood (400 sq. ft.)

b. Plaster/prosthetic laboratory (100 sq. ft)

c. Human remains and anthropology laboratory (dry laboratory and wet laboratory) with intraoral and extraoral X-ray facilities (400 sq. ft.)

\section{Forensic Odontology Kit}

\section{Equipment and kits for forensic odontology} department ${ }^{[11-14]}$

This article provides a basic classification and a comprehensive list of necessary equipment and kit that are required for the establishment of a forensic odontology department or unit.

The forensic odontology kit is a set of articles or equipment related to forensic odontology that is needed for a specific purpose.

Based on the place of application, the kit may be classified as follows:

1. Inhouse kit - the kit that is used indoor, within the organization, or institute

2. Field kit - the kit required at the crime scene or disaster site

Based on the application, the kit may be classified as follows:

1. Functional kit - those which are routinely used in real forensic cases and for research

2. Display/demo kit - those which are kept on display for teaching purposes. Some of the components are replicas of the original specimens

3. Training kit - those which are used for giving hands-on training to the students

The proposed armamentarium for the forensic odontology department is categorized as follows:

1. Investigative kit

2. Illumination kit

3. Personal protection equipment (PPE) kit

4. Documentation/stationery kit

5. Craniofacial Anthropology kit.

1. Investigative kit

a. Kit for DVI

- Protective clothing (see section 3)

- Clipboards plain

- Magnifying glasses

- Aluminum storage clipboards with integrated pen and pencil tray

- Plastic box with lids for collection of specimens such as dentures and teeth.

- Scene evidence number (yellow)

- Ready adhesive stickers/label

- Plastic transparent bags of various sizes

- Yellow measuring tape
- Compass

- Azimuth board

- Sketching templates

- Thermometer

- American Board of Forensic Odontology No. 2 scale

- Digital single-lens reflex camera with external flashlight

- Intraoral mirrors for photography

- Dental explorers

- Toothbrushes

- Autopsy twine

- Silk sutures

- Mallet and chisel

- Pruning shears

- Portable X-ray machine/handheld X-rays

- Sensor holders (Rinn and XCP)

- DVI antemortem and postmortem dental data recording forms

- Table for examining the resected anatomic and/ or skeletonized specimens

- Laptops with DVI software installed

- Scene paper evidence bags $(6 \times 9$ inches)

- Evidence box or cover sealing tapes and labels

- Battery-operated ultraviolet (UV) flashlight light-emitting diode (LED)

- Rechargeable 25W LED torchlight

- Magnifier/4xUV LED lighted handheld magnifier

- Magnets/telescopic pen magnets

- Dental impression trays - dentulous and edentulous

- Denture storage box with evidence labels

- Impression materials and stone plaster

- Camel hairbrush set

- Cyanoacrylate or nail polish to stabilize on the burnt teeth specimens

- Tongue blades/retractors

- Hydrogen peroxide

- Biohazard labels

- Hand and surface sanitizer

- Extra batteries (for all battery-operated devices)

- Permanent markers

- Storage boxes for small equipment

- Cleaning and sterilizing substances

b. Kit for lifting latent prints (lip print)

- Laminated fingerprint cards

- Lipstick (brown and red)

- Lipstick applicator

- Lipstick remover liquid

- Cotton balls/rolls

- Scissors

- Executive bond paper

- 2 " $\times 2$ " white hinge latent print lifter

- 2 " $\times 4^{\prime \prime}$ white hinge latent print lifter

- Inkpad

- Compact fingerprint cards 
Pillai, et al.: Proposed plan for establishing forensic odontology department

- Black powder for enhancing the print

- Powder brush

- Print lifting tape/cellophane tape

- Magnetic powder

- UV lamp

- Nitrile gloves

- Microscopes - stereomicroscope and comparison microscope

- PPE

- Handheld magnifier

- Laminated fingerprint type's identification cards

- Laminated lip print type's identification cards.

c. Kit for bite mark investigation

- Rubber-based impression material

- Nitrile gloves

- Impression trays

- Modeling wax.

- $\quad \mathrm{ABFO}$ No. 2 scale [Figure 4]

- Nuzzolese-Neri-DiVella No. 2 scale (colorimetric scale)

- 2" Photo scales

- Sterile cotton swab/applicators

- Stopwatch

- Universal buffer solution

- Bottled saline solution

- 20-200 $\mu \mathrm{L}$

- Standard reference manuals pipettes and pipette tips

- Tweezers

- Vortexes

- Saliva test strips

- Colored Eppendorf ${ }^{\circledR}$ tubes

- Microcentrifuges

- Microfuge tube racks

- Digital camera

- Laptops with image analysis softwares like Adobe Photoshop (Adobe Inc., San Jose, California, U.S.), GNU Image Manipulation Program (GIMP), ImageJ (NIH, Bethesda, Maryland, USA.), and AUTOCAD (Autodesk, San Rafael, California, USA)

- Flatbed scanner

- Inkpad to highlight the incisal/occlusal surfaces of the teeth on models.

- Inkjet color printers

- Tracing paper

- Thermometer

d. Kit for forensic facial reconstruction

- Reusable skulls with tissue-depth measuring pegs

- Small metric ruler

- Glue

- Scalpel or knife

- Nonhardening clay, tools, and materials

- Storage containers

- Super Sculpey (beige/red/yellow)

- 26-mm prosthetic eyes

- Clay tool (wood/rubber finish) e. Kit for age estimation

- Guidelines and standards manuals

- Dental anthropology manual

- Dental age atlases

- X-ray with radiovisiography compatibility

- X-ray viewer for orthopantomogram

- Computer with photo editing software

- Micromotor with straight and contra-angled handpiece

- Carbide and diamond tooth cutting discs

- Arkansas stone for tooth sectioning (coarse and fine)

- Bench lathe machine for tooth grinding

- Adjustable light source

- Glass slides with coverslips

- Microscopes - phase contrast

- Digital Vernier calipers

- Laminated chart showing stages of tooth development.

2. Illumination kit::[15]

a. Torchlight/Flashlight

b. $455 \mathrm{~nm}$ blue LED light

c. AC chargers, 100-240 VAC

d. Battery-operated UV light source $(495 \mathrm{~nm})$

e. Magnifier with LED light

f. Altered light source for viewing bite marks and latent prints

g. Forensic filters - clear, general, blue, orange, and green

h. Yellow goggle to view fresh bite mark

i. Orange goggles to view teeth and bone samples.

3. PPE kit

a. Tyvek cover coat

b. Laboratory apron

c. Tyvek sleeves

d. Overshoes

e. Mob cap/hairnet

f. Nitrile gloves

g. Face masks/eye protectors

h. Dispenser for gloves and masks

i. Forensic Goggles

j. N95 particulate respirators

k. Antimicrobial surface wipes

1. Antiseptic handwash

m. Biohazard trash bags

n. Green safety vest

o. Tyvek hair covers

- Order of putting on PPE ${ }^{[16]}$

1. Face mask

2. Mob cap

3. First pair of gloves

4. Over suite

5. Overshoes

6. Second pair of gloves

4. Documentation kit

a. Stationery kit 
Pillai, et al.: Proposed plan for establishing forensic odontology department

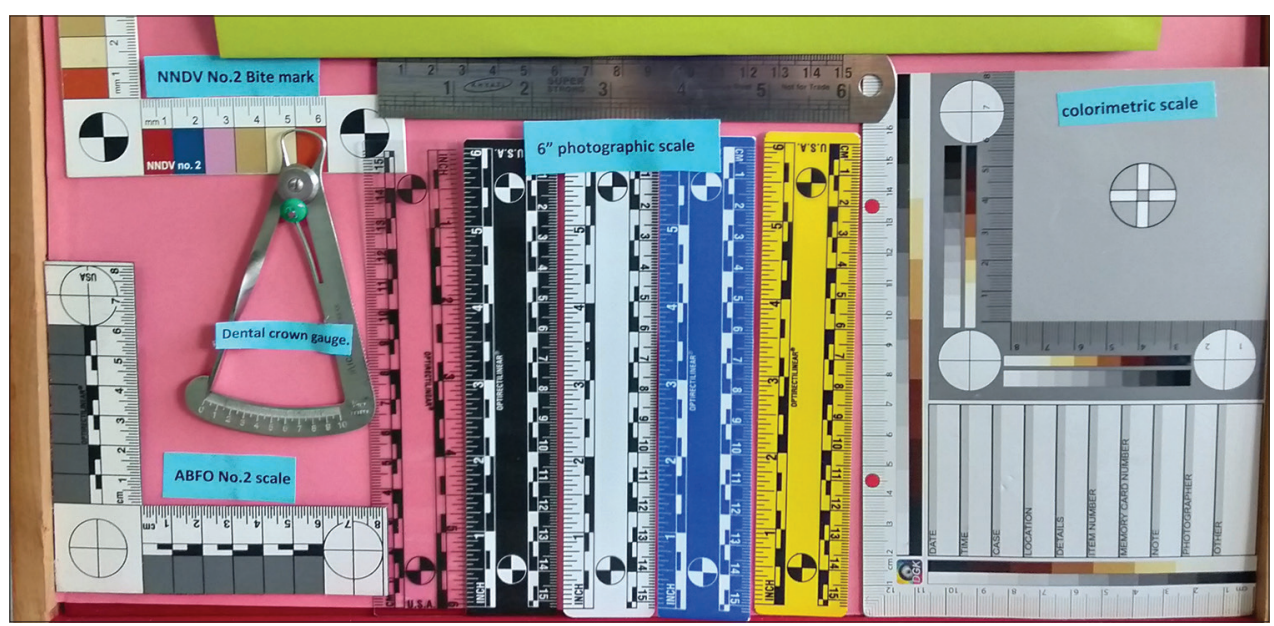

Figure 4: A customized kit of the principal author showing the different types of scales/rulers used in forensic odontology

- Clipboards

- Templates for sketch

- Permanent marker pen

- Color pencils for documenting the bite mark or any other injury

- HB pencils

- Lark for sealing the report covers

- Departmental letterhead mentioning the complete contact details

- Seal of the forensic odontologist mentioning the degree and designations

- Envelopes bearing the department and institutes details

- Pen drives

- DVI antemortem (Yellow) and postmortem (Pink) forms (hard and soft copy)

- Odontogram sheets

- Chain of custody sheets

- Logbook

- Countertop paper roll (21", $225 \mathrm{ft}$ long)

- Departmental files for individual cases

- Chain of custody labels $\left(31^{1 / 2} \times 5^{\prime \prime}\right)$

- Document cabinet

- Multifunctional flip chart.

b. Photo documentation kit

- 1-15 number photo markers

- 6" scale (white, gray, black, transparent, fluorescent, blue, and yellow)

- Photomacrographic scales

- 2" adhesive scales

- 12 ruler tape

- Field case

- Adhesive arrow booklet

- Auxiliary flash

- Evidence tape (13/8" $108 \mathrm{ft}$ )

- Evidence labels $\left(3 \frac{1}{2}\right.$ “ $\left.^{\prime \prime} 5^{\prime \prime}\right)$.

5. Craniofacial anthropology kit

a. Tooth development charts

b. $12 \times$ stainless steel small finds archeology tools c. $4 \times$ tweezers to allow to handle delicate finds

d. Plastic rulers

e. Protractors

f. Magnetic compass

g. Skull box

h. Measuring tape

i. Osteometric board

j. Comparative bone sets

k. Goniometer

1. Palatometer

m. ASUDAS plaques or Turner-Scott dental anthropology system [Figure 5]

n. Zipper closure bags

o. Comparative maxilla set

p. Comparative mandible set

q. Human skeleton - male and female

r. Skull-male and female, neonates' skull, primate skull

s. Skull - Mongoloid, Caucasoid, Negroid

t. Animal skulls (originals and replicas)

u. Animal teeth set

\section{Laboratory equipment}

Biotech laboratory

1. Bunsen burner

2. Laminar hood

3. Glasswares

4. Refrigerator with deep freeze

5. Pipettes and pipette tips

6. Chemicals and reagents

7. Centrifuge/ultracentrifuge

8. Weighing balance (digital)

9. Microscope-stereomicroscope, comparison microscope, and compound microscope

10. Hard tissue microtome

11. Photomicrographic camera

12. Disposal container

13. First aid kits

14. Portable fire extinguisher

15. Water bath 
Pillai, et al.: Proposed plan for establishing forensic odontology department

16. Oven

17. Hot plate

18. Incubators

19. Autoclave

20. $\mathrm{pH}$ meter

21. Distilled water plant

22. Rotary shaker

23. Electric heater

24. Petri dish

25. Conical flasks

26. Culture tubes

27. Beakers

28. Funnels

29. Measuring jars

30. Graduated and bulb pipettes

31. Burettes

32. Reagent bottles

33. Glass slides and coverslips

34. Nonabsorbent cotton

35. Tissue paper

36. Aluminum foil

37. Test tube stands

38. Glass marking pencil

39. Cabinets for storing chemicals and glassware.

40. Disinfectants

41. Micromotor and carbide discs for tooth sectioning

42. Bench lathe machine for tooth grinding

43. Mortar and pestle for tooth crushing (Ceramic or Metal)

44. Digital Vernier caliper

45. Handheld or stand-mounted digital microscope $(10 \times-80 \times)$.

\section{Prosthetic laboratory}

1. Model trimmer

2. Dental articulators

3. Vacuum mixer cum vibrator

4. Modelling wax

5. Cyanoacrylate cement

6. Base former

7. Die stone

8. Dental plaster

9. Impression materials

10. Teeth shade guide

11. Dental laboratory 3D scanners (Benchtop) and 3D printer

12. Slow set alginate for replicating skull in facial reconstruction.

\section{Anthropology laboratory}

1. Stainless steel table with individual water hoses for the wet analysis of the skeletal specimens

2. Wooden table for the dry analysis of specimens.

Note: The additional specialized equipment may be made available through cooperative agreements with associates within the institute or on the campus.

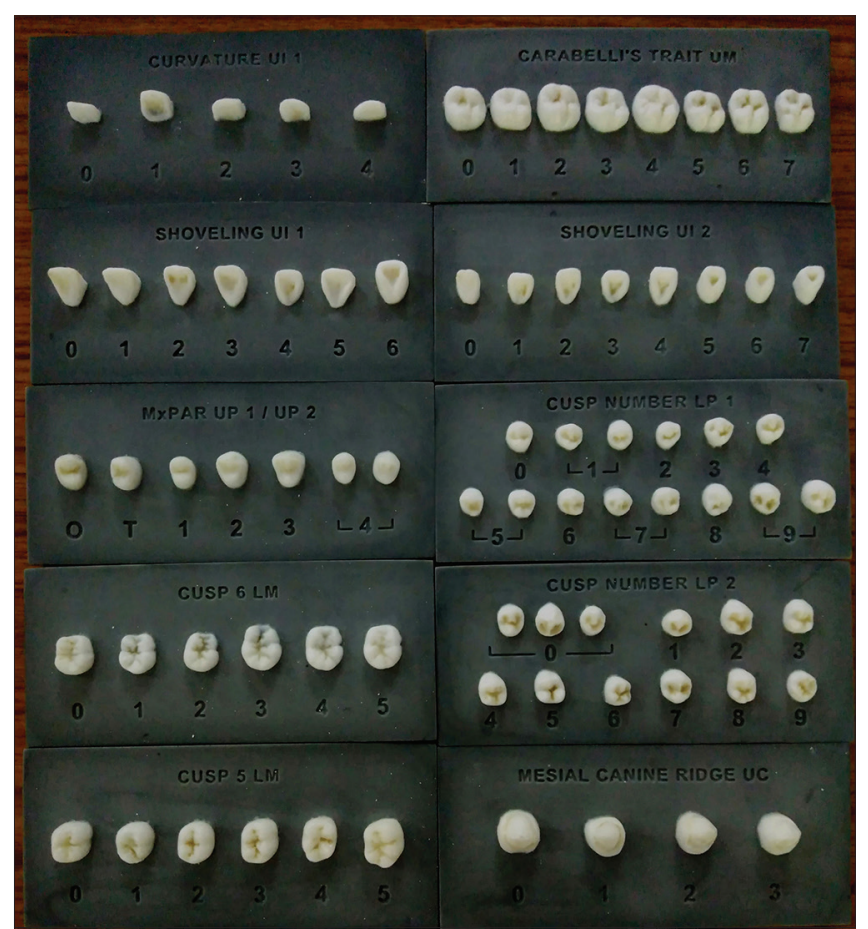

Figure 5: The plaques of 10 nonmetric dental traits of the Turner-Scott dental anthropology system

\section{Library}

1. 15-20 titles of renowned authors

2. 4-6 international journals

a. Forensic Science International

b. Journal of Forensic Odontostomatology

c. International Journal of Legal medicine

d. Journal of Forensic Dental Sciences

e. Journal of Forensic Sciences

3. $8-10$ volumes of back issues of at least three international journals

4. $50 \%$ in the print form

5. Computers with internet connection for online access.

\section{Seminar room}

1. LCD projector/digital screen

2. Notice board

3. Seating arrangements

4. Microphones and speakers

5. Computer

6. Audio-Visual (AV) adapters

7. Educational videos/tubes

8. Facility for webinars and live AV communications

9. Facility for Mock court.

\section{Museum section}

1. Dental models and charts showing different dental nonmetric traits

2. Skull models

3. Human skeleton - male and female

4. Histology images of neonatal lines and cemental annulations 
Pillai, et al.: Proposed plan for establishing forensic odontology department

5. Recorded bite mark images of different domestic animals and wild animals

6. Table models for DVI phases

7. Facial reconstruction models in different stages

8. Skulls and teeth of different animals

9. Skulls of neonates

10. Charts or bone replicas illustrating different age estimation methods

11. Charts illustrating different dental notations system and dental codes

12. Portrait or photographs of eminent forensic odontologists

13. Manuals and guidelines released by forensic odontology associations or organizations.

\section{Radiology section}

1. Handheld X-ray machine

2. RVG

3. Skull positioning devices

4. Computer for imaging observation and archive

5. Lead aprons

6. Lead gloves

7. Thyroid collar

8. Lead screen

9. Darkroom facility

10. Dosimeter badges

11. Automatics X-ray developer

12. X-ray viewer box with adjustable illumination.

\section{Engineering section}

1. Fire protection

2. Electrical

3. Air conditioning

4. Refrigeration

5. Water supply

6. Disposal system

7. Power backups

8. Fire and rescue tools and equipment.

\section{Miscellaneous}

1. Letter of permissions or memorandum of understanding by the Government for handling forensic dental evidence and cases (mandatory for private dental institutes)

2. Record book/logbook

3. Refrigerator

4. Cupboard

5. Loupes

6. Skinfold caliper

7. Weighing machine

8. Height measuring tapes, Stadiometer

9. Mid-arm circumference measuring tapes.

The above model and the armamentarium list have been prepared by the authors based on their experience in the field of forensic odontology. The corresponding author has 5 years of experience in forensic odontology case works, plus over 21 years of teaching experience in Government dental institute. The coauthors are trained forensic odontologists. The last coauthor is a forensic odontologist with huge international experience in several DVI teams and international law enforcement agencies, including Interpol, with 17 years of experience.

\section{Conclusion}

All domains of forensic odontology need to be taught by trained and qualified forensic odontologists who are familiar with the medico-legal criteria, methodologies, standards, international guidelines, civil and penal responsibilities. Forensic odontology is the unique branch of dentistry that bridges the Ministry of Health, Ministry of Home affairs in any state government with interaction from military and foreign affairs, too. For this reason, a forensic odontology specialized unit shall be recognized by state home ministry and gain an affiliation with the state FSL. The forensic odontology department or unit in any dental institute may require infrastructure and technical support with experienced dentists having training or postgraduate degree in forensic odontology and forensic sciences experiences. The dental education system in our country needs to ensure that the training in forensic odontology to the dental students meets the standards appropriate to the future needs of dental professions by establishing a dedicated department for forensic odontology at dental institutes. This present article for the first time addresses the need for the establishment of a forensic odontology unit in dental institutes along with a proposed infrastructure model. It is wise to mention that not all the above-mentioned list of equipment and infrastructure are essential to establish a forensic odontology department, but some may consider many of them as being important. It may also provide a readymade checklist to help forensic odontologists wishing to establish a specific unit or department in any academic set up.

\section{Acknowledgment}

The authors wish to acknowledge the efforts of Ar. Saravana Balaji (M.Arch), Architect, based in Chennai for designing a suitable plan for the department of Forensic odontology. The subject inputs based on the first author's personal interaction with some renowned forensic experts/ authors such as Dr. Ashith Acharya (India), Dr. Jayanie Weeratna (Sri Lanka), Dr. Marin Vodanovic (Croatia), Dr. Khalid (Sudan), Dr. Vilma Pinchi (Italy), Dr. Vijay Reesu (Scotland), Dr. Hemalata Pandey (India), Dr. Samantha Thakur (India), Dr. Sudhir Bhalla (India), Dr. Prabhakaran Nambiar (Malaysia), Dr. Jayakumar Jayaraman (Malaysia), Dr. Adarsh Kumar (India), Dr. Anil Agarwal (India), Dr. Roberto Cameriere (Italy), Dr. Patrick Thevissen (Belgium), and Dr. Sigrid Kvaal (Norway) during the forensic odontology conferences held in India were also very useful during the preparation of this manuscript. The 
Pillai, et al.: Proposed plan for establishing forensic odontology department

authors thank them for sharing their valuable expertise on forensic odontology.

\section{Financial support and sponsorship \\ Nil.}

\section{Conflicts of interest}

There are no conflicts of interest.

\section{References}

1. Acharya $A B$, Sivapathasundharam B. Forensic odontology. In: Shafer's Textbook of Oral Pathology. $5^{\text {th }}$ ed. India: Elsevier; 2006. p. 1199-227.

2. Available from: http://www.dciindia.gov.in/. [Last accessed on 2019 Feb 25].

3. Available from: https://www.jssuni.edu.in/JSSWeb/UDData/Docs/ Dental-MSc-Forensic-OdontologySylbs.pdf. [Last accessed on 2019 Feb 25].

4. Available from: https://www.gfsu.edu.in/institute-offorensic-science/programs-ifs/. [Last accessed on 2019 Feb 25].

5. Available from: https://www.tnmgrmu.ac.in/images/ Syllabus-and-curriculam/post-doctorial-fellowship/pdf-ForensicDentistry.pdf. [Last accessed on 2019 Feb 25].

6. Dinkar AD. Forensic odontology: Trends in India. J Forensic Dent Sci 2014;6:1-2.

7. Available from: http://www.dciindia.gov.in/Rule_Regulation/
Revised_BDS_Course_Regulation_2007.pdf. [Last accessed on 2019 Feb 25].

8. Available from: https://www.sdmcds.org/forensic-odontology. [Last accessed on 2019 Feb 28].

9. Nuzzolese E, Di Vella G. Future project concerning mass disaster management: A forensic odontology prospectus. Int Dent J 2007;57:261-6.

10. Jeddy N, Ravi S, Radhika T. Current trends in forensic odontology. J Forensic Dent Sci 2017;9:115-9.

11. INTERPOL Disaster Victim Identification Guide. Lyon: INTERPOL 2009. Available from: https://www.interpol.int/en/content/ download/589/file/18Y1344\%20E\%20DVI_Guide.pdf. [Last accessed on 2019 Jun 05].

12. Morgan TB, van A. Management of Dead Bodies after Disasters: A Field Manual for First Responders. Washington, DC: Pan American Health Organization, World Health Organization, ICRC, International Federation of Red Cross and Red Crescent Societies; 2009. p. 64.

13. Senn DR, Weems RA. Manual of Forensic Odontology. $5^{\text {th }}$ ed., Boca Raton, FL: Taylor and Francis; 2013.

14. Silver WE, Souviron Richard R. Dental Autopsy. Boca Raton, FL: CRC Press; 2009.

15. Forensic Science Regulator. Available from: http://www.gov. uk/government/organisations/forensic-science-regulator. [Last accessed on 2019 Mar 26].

16. Available from: http://www.horiba.com/fieldadmin/uploads/ Scientific/Documents/Forensics/fls.pdf. [Last accessed on 2019 Mar 25]. 